\title{
REVIEW
}

\section{Prescribing exercise training in pulmonary rehabilitation: A clinical experience}

\author{
S. Bernard, F. Ribeiro, F. Maltais, D. Saey*
}

Centre de Recherche, Institut Universitaire de cardiologie et de pneumologie de Québec, Université Laval, Québec, Canada

Received 25 October 2013; accepted 30 October 2013

Available online 28 January 2014

\section{KEYWORDS \\ Pulmonary \\ rehabilitation; \\ Exercise training; \\ Clinical experience}

\begin{abstract}
Built around exercise training, pulmonary rehabilitation (PR) is a multidisciplinary, evidence-based, comprehensive approach to working with the patient as a whole and not just the pulmonary component of the disease. Integrated into the individualized treatment, this intervention aims to reduce symptoms, optimize functional status, increase participation in daily life, and reduce health care costs through stabilizing or reversing systemic manifestations of the disease. Although there are many other components that should be considered to manage the impairment and symptom burden, supervised exercise training is considered the cornerstone of effective pulmonary rehabilitation. This paper addresses our clinical experience at Institut universitaire de cardiologie et de pneumologie de Québec to assess and manage exercise training in line with the current recommendations and guidelines surrounding PR.

(c) 2013 Sociedade Portuguesa de Pneumologia. Published by Elsevier España, S.L. All rights reserved.
\end{abstract}

\section{Prescrição de exercício físico na reabilitação pulmonar: uma experiência clínica}

Resumo Construída com base no exercício físico, a reabilitação pulmonar (RP) é uma abordagem multidisciplinar, fundamentada e abrangente para trabalhar com o doente como um todo, e não apenas com a componente pulmonar da doença. Integrado no tratamento individual, esta intervenção visa reduzir os sintomas, optimizar o estado funcional, aumentar a participação na vida diária e reduzir os custos do tratamento de saúde, através da estabilização ou inversão das manifestações sistémicas da doença. Embora existam muitos outros componentes que devem ser tidos em consideração para gerir o peso da incapacidade e dos sintomas, o exercício físico supervisionado é considerado o fundamento da reabilitação pulmonar eficiente. Este documento trata da nossa experiência clínica no Institut universitaire de cardiologie et de pneumologie de Québec para avaliar e gerir o exercício físico em linha com as recomendações e orientações actuais envolvendo a RP.

(C) 2013 Sociedade Portuguesa de Pneumologia. Publicado por Elsevier España, S.L. Todos os direitos reservados.

\footnotetext{
* Corresponding author.

E-mail address: didier.saey@criucpq.ulaval.ca (D. Saey).
}

0873-2159/\$ - see front matter @ 2013 Sociedade Portuguesa de Pneumologia. Published by Elsevier España, S.L. All rights reserved. 


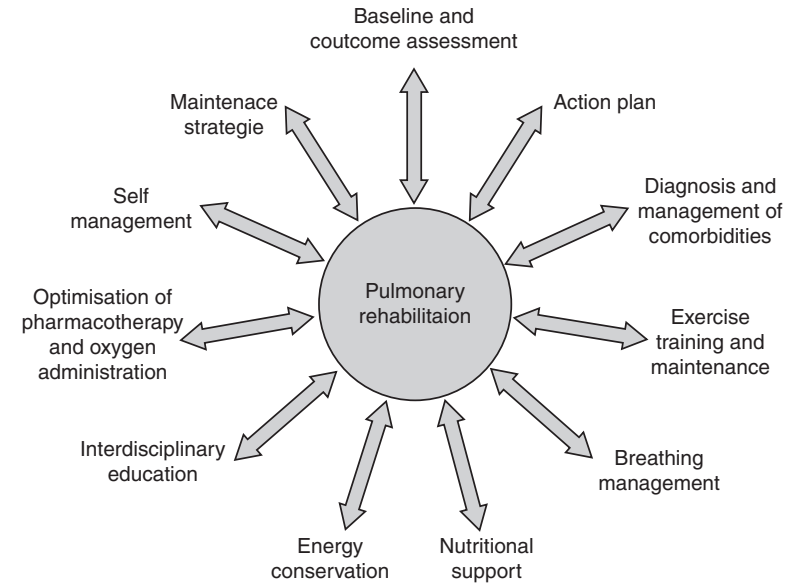

Figure 1 Key components of pulmonary rehabilitation.

\section{Introduction}

Chronic obstructive pulmonary disease (COPD) is a major cause of morbidity and mortality wordwide and it is expected that by 2020 COPD will be the fifth most burdensome disease and the third leading cause of mortality. ${ }^{1}$ The natural course of the disease is punctuated by episodes of acute exacerbation which contribute to the increased morbidity and mortality and socioeconomic burden associated with COPD. ${ }^{2}$ Patients with COPD frequently show exercise intolerance and dyspnea, reduced ability to participate in activities of daily living, reduced health-related quality of life and increased use of health care resources. ${ }^{3}$ If optimal bronchodilation can be seen as a first step in the treatment of patients with COPD, more effective treatments (e.g., improvements in exercise performance, symptoms, and health-related quality of (ife) are often achieved after pulmonary rehabilitation (PR). ${ }^{4}$ Comprehensive PR aims at tackling the systemic consequences of COPD and also the behavioral and educational shortcomings observed in many patients and it is now widely recognized as an effective and key intervention in the management of COPD. ${ }^{1,5-10}$ It is also suggested that PR appears to be cost-effective, it decreases utilization of health care services. ${ }^{11,12}$

\section{Pulmonary rehabilitation definition, concept and setting}

Built around exercise training, PR is a multidisciplinary, evidence-based comprehensive approach to addressing the patient as a whole and not only the pulmonary component of the disease (Fig. 1). Integrated into the individualized treatment of the patient, PR is individually tailored and designed to reduce symptoms, optimize functional status, increase participation, and reduce health care costs through stabilizing or reversing systemic manifestations of the disease. ${ }^{5,8,10,13-17}$

In a broader sense, PR includes a spectrum of strategies integrated into the lifelong management of patients with chronic respiratory disease and involves a dynamic and active collaboration between patients, families, and health care providers. Pulmonary rehabilitation typically includes individualized patient assessment, supervised exercise training, self-management education, psychosocial support and nutritional counseling. ${ }^{5,10}$ Patients are usually enrolled in a 6-12-week exercise program which they attend 2-3 times per week.

Individualized patient assessment should include medical history, physical exam and accurate diagnosis of their respiratory condition based on pulmonary function testing and detection of comorbidities that may interfere with the rehabilitation process. ${ }^{10}$ Baseline assessment should also comprise measures of exercise capacity, symptoms and quality of life. ${ }^{18}$ Hypoxemia at rest and during effort is what should be looked for.

Exercise training is the cornerstone of effective PR and preferably includes both aerobic and muscle training. To achieve clinically relevant results, training should be closely supervised and performed for 30-45 min, at least 3 days per week. Patients should undertake a minimum of 20 sessions, but longer programs produce broader and more long-lasting results. ${ }^{5,16,19-22}$

Nutritional intervention should be considered for patients with body composition abnormalities such as cachexia and obesity which is becoming one of the most prevalent nutritional issues in COPD. ${ }^{23}$ Patients with fears and anxiety may benefit from psychosocial support and the integration of occupational therapy in PR can improve autonomy in activities of daily living. Moreover, in order to facilitate chronic disease self-management there are other areas of importance: these include approaches designed to (1) facilitate smoking cessation; (2) optimize pharmacotherapy; (3) assist with early identification and treatment of acute exacerbations; (4) manage acute dyspnea; (5) increase physical activity; (6) improve body composition; (7) promote mental health; (8) facilitate advance care planning; and (9) establish social support networks. ${ }^{24}$ Finally, strategies to promote a more active lifestyle following PR, such as the implementation of a home exercise program should be considered.

Pulmonary rehabilitation can be effective as inpatient, hospital- or community-based outpatient, or home-based programs. ${ }^{5,15,25}$ Inpatient programs are generally more expensive and suitable for patients with limited transportation or severe deconditioning requiring specific resources such as nutritional supplementation or training for home ventilation. ${ }^{8}$ Because outpatient programs offer rehabilitation with secure and predictable improvements at a relatively low cost, multidisciplinary PR programs are typically implemented in outpatient hospital- or communitybased settings. Home-based exercise programs are also effective in improving exercise tolerance and quality of life. ${ }^{26,27}$ Home-based rehabilitation is well suited for highly motivated, self-directed individuals but appears to be less successful with severe, homebound patients. ${ }^{28,29}$ Homebased rehabilitation is particularly effective in maintaining improvements obtained in an outpatient setting ${ }^{30}$

\section{Assessment in pulmonary rehabilitation}

In order to guide assessment and prescription of exercise training in PR programs, cardiorespiratory exercise capacity and limb muscle function are the essential components to be evaluated. As there are several tests available; a summary of the most common validated tests, as well as their essential 
Table 1 Physical function assessment examples.

\begin{tabular}{|c|c|c|c|c|c|c|}
\hline Components & Tests & Aims & Administration & Main outcomes & Advantages & Limitations \\
\hline \multirow[t]{5}{*}{ Exercise capacity } & $\begin{array}{l}\text { Symptom-limited } \\
\text { maximal } \\
\text { incremental } \\
\text { cardiopulmonary } \\
\text { test (CPET) }\end{array}$ & $\begin{array}{l}\text { Aerobic } \\
\text { cardiorespiratory } \\
\text { exercise capacity }\end{array}$ & $\begin{array}{l}5-20 \mathrm{~W} \text { increment per } \\
\text { minute, until exhaustion } \\
8-12 \text { min } \\
\text { Treadmill or bicycle }\end{array}$ & $\begin{array}{l}\text { Peak work rate } \\
\text { Cardiorespiratory } \\
\text { function variables } \\
\text { (Peak } \mathrm{HR}, \mathrm{RR}, \\
\dot{\mathrm{V}} \mathrm{O}_{2}, \dot{V} \mathrm{CO}_{2}, \dot{V} E \\
\text { operational } \\
\text { volumes, etc.) }\end{array}$ & $\begin{array}{l}\text { Reliability and validity } \\
\text { Cardiopulmonary } \\
\text { function diagnostic } \\
\text { Evaluation of } \\
\text { cardiovascular risk } \\
\text { Anaerobic threshold } \\
\text { determination }\end{array}$ & $\begin{array}{l}\text { Equipment and certified } \\
\text { personnel-related costs }\end{array}$ \\
\hline & $\begin{array}{l}\text { Constant-rate } \\
\text { cardiopulmonary } \\
\text { test }\end{array}$ & $\begin{array}{l}\text { Endurance } \\
\text { cardiorespiratory } \\
\text { exercise capacity }\end{array}$ & $\begin{array}{l}\text { Constant work rate } \\
\text { proportional to peak } \\
\text { exercise capacity (e.g., } \\
60 \% \text { of peak work rate), } \\
\text { until exhaustion } \\
\text { Treadmill or bicycle }\end{array}$ & $\begin{array}{l}\text { Time until } \\
\text { exhaustion } \\
\text { Cardiorespiratory } \\
\text { function variables }\end{array}$ & $\begin{array}{l}\text { Greater sensitivity to } \\
\text { identify changes after } \\
\text { intervention } \\
\text { Cardiopulmonary } \\
\text { function diagnostic } \\
\text { Cardiovascular risk } \\
\text { assessment }\end{array}$ & $\begin{array}{l}\text { Requires a previous } \\
\text { maximal test Equipment } \\
\text { and certified } \\
\text { personnel-related costs }\end{array}$ \\
\hline & 6-min walk test & $\begin{array}{l}\text { Functional } \\
\text { exercise capacity }\end{array}$ & $\begin{array}{l}\text { Walking back and forth } \\
\text { on a } 30-\mathrm{m} \text { course } \\
\text { Self-paced speed }\end{array}$ & $\begin{array}{l}\text { Total distance } \\
\text { walked in } 6 \mathrm{~min}\end{array}$ & $\begin{array}{l}\text { Reliability and validity } \\
\text { Low complexity and cost } \\
\text { Good correlation with } \\
\text { activities of daily living }\end{array}$ & $\begin{array}{l}\text { Does not provide } \\
\text { cardiopulmonary } \\
\text { diagnosis } \\
\text { No detailed information } \\
\text { on physiological } \\
\text { variables }\left(\dot{V} O_{2}, \dot{V} E\right) \text { and } \\
\text { exercise limitation } \\
\text { mechanisms } \\
\text { May require a previous } \\
\text { familiarization test }\end{array}$ \\
\hline & $\begin{array}{l}\text { Incremental } \\
\text { shuttle-walk test }\end{array}$ & $\begin{array}{l}\text { Functional } \\
\text { exercise capacity }\end{array}$ & $\begin{array}{l}\text { Walking back and forth } \\
\text { on a } 10 \text {-m course with } \\
\text { paced-increments of } \\
\text { walking speed, until } \\
\text { inability to keep the } \\
\text { pace }\end{array}$ & $\begin{array}{l}\text { Total distance } \\
\text { walked until } \\
\text { exhaustion }\end{array}$ & $\begin{array}{l}\text { Fast to prepare and } \\
\text { perform } \\
\text { Good correlation with } \\
\dot{\mathrm{V}} \mathrm{O}_{2} \text { max in CPET } \\
\text { Low cost }\end{array}$ & $\begin{array}{l}\text { Higher risk of } \\
\text { cardiovascular events } \\
\text { Less widespread use } \\
\text { Subject to patient } \\
\text { motivation }\end{array}$ \\
\hline & $\begin{array}{l}\text { Endurance } \\
\text { shuttle-walk test }\end{array}$ & $\begin{array}{l}\text { Endurance } \\
\text { functional } \\
\text { exercise capacity }\end{array}$ & $\begin{array}{l}\text { Walking back and forth } \\
\text { on a } 10-\mathrm{m} \text { course with } \\
\text { fixed paced of walking } \\
\text { speed, until inability to } \\
\text { keep the pace }\end{array}$ & $\begin{array}{l}\text { Time until } \\
\text { exhaustion }\end{array}$ & $\begin{array}{l}\text { Good correlation with } \\
\text { CPET cardiorespiratory } \\
\text { response } \\
\text { Reliability, validity, } \\
\text { responsiveness } \\
\text { Low complexity and cost }\end{array}$ & $\begin{array}{l}\text { Requires a previous } \\
\text { incremental shuttle test } \\
\text { Same as incremental } \\
\text { shuttle test }\end{array}$ \\
\hline
\end{tabular}




\begin{tabular}{|c|c|c|c|c|c|c|}
\hline Components & Tests & Aims & Administration & Main outcomes & Advantages & Limitations \\
\hline \multirow[t]{3}{*}{ Limb muscle strength } & $\begin{array}{l}\text { Isometric maximal } \\
\text { Voluntary } \\
\text { contraction }\end{array}$ & $\begin{array}{l}\text { Muscle strength of } \\
\text { lower and/or } \\
\text { upper limbs }\end{array}$ & $\begin{array}{l}3 \text { reproducible maximal } \\
\text { contractions at a fixed } \\
\text { joint angle }\end{array}$ & Peak muscle force & $\begin{array}{l}\text { Validity and reliability } \\
\text { Low cost } \\
\text { Good association with } \\
\text { prognosis }\end{array}$ & $\begin{array}{l}\text { Less physiological than } \\
\text { concentric movements }\end{array}$ \\
\hline & $\begin{array}{l}1 \text { Repetition } \\
\text { maximum (1RM) }\end{array}$ & $\begin{array}{l}\text { Muscle strength of } \\
\text { lower and/or } \\
\text { upper limbs }\end{array}$ & $\begin{array}{l}\text { Maximal load beared to } \\
\text { perform one full-range } \\
\text { contraction with no } \\
\text { compensatory } \\
\text { movements } \\
\text { OR } \\
\text { Maximal load bared to } \\
\text { perform } 6-12 \text { repetitions }\end{array}$ & Maximal load & $\begin{array}{l}\text { Feasible in clinical } \\
\text { setting } \\
\text { Concentric, more } \\
\text { physiological movements } \\
\text { Specificity between test } \\
\text { and training movements }\end{array}$ & $\begin{array}{l}\text { Difficulty to establish in } \\
\text { patients susceptible to } \\
\text { fatigue } \\
\text { Standardization and } \\
\text { variability among } \\
\text { different clinical settings }\end{array}$ \\
\hline & $\begin{array}{l}\text { Isokinetic } \\
\text { contractions }\end{array}$ & Muscle strength & $\begin{array}{l}\text { 2-5 repeated maximal } \\
\text { contractions at a given } \\
\text { constant velocity }\end{array}$ & Peak torque & $\begin{array}{l}\text { No influence of } \\
\text { movement angular } \\
\text { velocity } \\
\text { Validity and reliability to } \\
\text { different populations } \\
\text { (older, COPD) }\end{array}$ & $\begin{array}{l}\text { Isokinetic contraction } \\
\text { are not natural } \\
\text { movements } \\
\text { Equipment costs } \\
\text { Familiarization required }\end{array}$ \\
\hline Limb muscle endurance & $\begin{array}{l}\text { Repeated } \\
\text { voluntary } \\
\text { contractions }\end{array}$ & Muscle endurance & $\begin{array}{l}\text { Repeated contractions at } \\
\text { proportion of maximal } \\
\text { force until exhaustion or } \\
\text { reduction }>80 \% \text { of the } \\
\text { target } \\
\text { OR } \\
\text { A given number of } \\
\text { repeated contractions at } \\
\text { a fixed load (isotonic) or } \\
\text { constant velocity } \\
\text { (isokinetic) }\end{array}$ & $\begin{array}{l}\text { Time to task } \\
\text { failure } \\
\text { OR } \\
\text { Total work } \\
\text { performed }\end{array}$ & $\begin{array}{l}\text { More related to } \\
\text { oxidative metabolism } \\
\text { than strength } \\
\text { Potential to higher } \\
\text { sensitivity to } \\
\text { intervention than } \\
\text { strength } \\
\text { Low cost }\end{array}$ & $\begin{array}{l}\text { Lack of standardization, } \\
\text { validation and protocols } \\
\text { comparison trials } \\
\text { Reliability to be } \\
\text { demonstrated }\end{array}$ \\
\hline
\end{tabular}


characteristics, is presented in Table 1. In clinical practice, the training objectives and the availability of resources will influence the choice of the tests to be used.

\section{Assessments of cardiopulmonary exercise capacity}

\section{Cardiopulmonary exercise tests}

Cardiopulmonary exercise testing is the best recognized way to assess exercise capacity and cardiovascular risk. The ATS-ACCP statement provides a good description of the recommendations for cardiopulmonary exercise tests. ${ }^{31}$

Incremental maximal cycling or treadmill cardiopulmonary tests allow medical staff to prescribe precisely the intensity endurance training based on physiological responses to variables such peak heart rate, ventilation $(\dot{V} E)$, oxygen consumption $\left(\dot{V} \mathrm{O}_{2}\right), \mathrm{CO}_{2}$ output $\left(\dot{V} \mathrm{CO}_{2}\right)$ and respiratory exchange ratio (RER). A constant work rate cardiopulmonary test in which patients are asked to exercise as long as possible at a submaximal work rate is also recommended. The constant work rate test is clinically pertinent to PR programs because of its excellent sensitivity which enables it to identify changes after exercise training or other therapeutic interventions. ${ }^{32,33}$

Although cardiopulmonary exercise testing is relevant and recommended, it is also more expensive, complex and requires more resources and so tends to be implemented more frequently in highly specialized centers. In addition to the laboratory based tests of exercise capacity, field-based tests can be undertaken with minimal resources. Although less complex and less costly, they must not be simply considered as substitutes for cardiopulmonary tests.

\section{Walking tests}

The 6-min walk-test (6MWT) is the most widely used fieldbased test in clinical and research settings. ${ }^{34}$ Walking is a reflection of the integrated respiratory, cardiovascular and neuro-muscular responses to exercise. The distance walked results from the combination of all systems involved in the task of walking and it would be difficult to know which of these systems plays a major limiting role in task failure. Patients who experience severe breathlessness, for example, might reduce walking speeds during self-paced tests to avoid unpleasant respiratory symptoms. This test is also believed to reflect functional status in daily activities better than the cardiopulmonary tests. ${ }^{34,35}$ In general, $6 M W T$ is considered a submaximal functional test. Due to the familiarization effect, performing at least two tests is recommended. ${ }^{34}$ Using the established recommended protocol is critical to obtaining reliable, valid, and reproducible test results. ${ }^{34}$

Walking test may also be carried out using incremental and endurance shuttle walking tests. The incremental shuttle walking test is an externally paced maximal exercise test; the speed of walking is controlled by a series of pre-recorded signals played from a CD. The speed of walking increases until the participant can no longer continue. For the endurance shuttle walking test patients need to walk as long as possible at a predetermined speed calculated from the incremental shuttle walking test. Detailed indications, contraindications and technical aspects are available elsewhere. ${ }^{34,36}$
Finally, the assessment of symptom perception during both laboratory and field-based tests is strongly recommended and is a useful guide for exercise prescription. ${ }^{31}$ Thus, patients may easily indicate their perceptions of dyspnea and leg fatigue throughout the tests by the 10-point modified Borg scale, which is the most widely used in PR programs.

\section{Assessment of limb muscles function}

We encourage routine assessment of limb muscle function before pulmonary rehabilitation as this provides important information about the mechanisms of exercise limitation. Also, knowledge of limb muscle function may help in the drawing up of individual training programs.

\section{Muscle strength}

There are several tests available to quantify muscle strength. ${ }^{37}$ Isometric maximal voluntary contractions using strain gauge remains a preferred method of easily assessing volitional strength in clinical practice. ${ }^{38}$ Muscle contractions are performed at a fixed joint angle. It is a highly reproducible and sensitive method when standardization is respected. However, it can be less relevant to movements made during training sessions which are often isotonic concentric contractions, such as weight lifting. For example, a one-repetition maximum (1RM) is a widely used evaluation method in which strength is defined as "the maximal amount of weight that can be lifted through the full range of motion, for one repetition, with proper form' '. ${ }^{39}$ However, choosing this optimal load may be challenging and time-consuming for patients who are more susceptible to muscle fatigue, such as COPD patients. ${ }^{40}$ An example of a 1 RM test is provided in Table 1. The advantage is that this load may serve as a baseline from which to start training.

Many other tools and equipment may be useful for measuring muscle strength such as manual muscle testing, isokinetic dynamometers, hand-held dynamometers, hydraulic resistance, peripheral and transcranial magnetic stimulation. Careful analysis of each assessment tool validity, reliability and cost-benefit is mandatory before implementing their use.

\section{Muscle endurance}

The capacity of muscles to sustain a required task for as long as possible, labeled as "muscle endurance", is more often associated with muscle aerobic capacity ${ }^{41}$ and less determined by muscle mass than muscle strength ${ }^{42}$. Moreover, measures of muscle endurance may be more sensitive to detecting changes associated with exercise training than muscle strength. In addition, muscle endurance cannot be predicted from muscle strength, providing an additional rationale for its measurement before exercise training. ${ }^{43}$ Unfortunately, we still do not know which assessment tools would best reflect improvements in muscle endurance, especially considering the nature and intensity of the exercise training protocol applied. In addition, no direct comparisons between different endurance protocols, no standardization and no reference values are available. These deficiencies may explain why assessment of limb muscle endurance is not more widely applied in clinical practice. 
In Table 1, some suggestions are provided given the current available data on muscle endurance assessment. Consideration should be given to the fact that exercises promoting muscle endurance may help patients to develop higher muscle tolerance, thereby favoring tolerance during whole-body exercise training such as walking and cycling.

\section{Quebec experience}

The current format of the PR program at the Institut universitaire de cardiologie et de pneumologie de Québec started in 1992 under the leadership of Dr. Roger Belleau, a visionary pulmonologist, who devoted his medical practice to the improvement of care for patients with chronic respiratory disease. The development of a PR program was not an obvious thing to do back in early 90s when skepticism about the effectiveness of this intervention was common in the medical community. ${ }^{44}$ Since then, PR has come a long way and is now considered as a standard of care in COPD with all the benefits supported by an important body of literature already reported in the first part of this article. ${ }^{10,17}$

Our PR program is a multidisciplinary 12 -week outpatient, hospital-based program. It includes pre-program assessment, self-management teaching program, exercise training program, maintenance program and post-program assessment. We are currently implementing a wellstructured home-rehabilitation program to be carried out in the community but coordinated from the hospital.

The patients are usually referred by the doctors or the nurses and respiratory therapists of the COPD clinic which offers a unique opportunity of convincing patients about the efficacy of pulmonary rehabilitation. The coordinating nurse takes patients through the evaluation process and selfmanagement program. Exercise specialists (kinesiologists and physiotherapists) supervise the exercise component of the program and offer advice on the selection of the most appropriate strategies for maintenance strategy and for the development of a more active daily life.

\section{Pre-program assessment}

All the patients undergo a maximal incremental and symptom-limited exercise test on a cycle ergometer. ${ }^{45}$ Maximal exercise testing provides peak work rate, peak heart rate, and also information on arterial blood pressure, pulse oxygen saturation $\left(\mathrm{SpO}_{2}\right)$, dyspnea, leg fatigue and ECG changes during effort. This evaluation in the context of supervised PR allows for the planning of the intensity and progression of aerobic training. An endurance test is also routinely performed on a cycle ergometer at a constant work load equivalent to $80 \%$ of peak work load during incremental testing. We measure the time that can be sustained at a pedaling rate above $40 \mathrm{rpm}$. Six-min walk distance, spirometry, body composition analysis by bioelectrical impedance, waist circumference and arterial blood gases are also obtained. In patients with COPD, the impact of disease on a person's life is determined by the COPD Assessment test. (CAT) questionnaire. ${ }^{46}$ Possible barriers that could impinge on the progression and success of the program are identified in every patient. Finally, quantification of physical activities during daily life, respiratory muscle strength and 1 maximal
Table 2 Self-management teaching program at IUCPQ.

\begin{tabular}{lll}
\hline & $\begin{array}{l}\text { No. of } \\
\text { sessions }\end{array}$ & $\begin{array}{l}\text { No. of hours } \\
\text { per session }\end{array}$ \\
\hline $\begin{array}{l}\text { Kinesiologist (exercise training } \\
\quad \text { and maintenance) }\end{array}$ & 1 & 3 \\
$\begin{array}{l}\text { Physiotherapist (exercise } \\
\text { training and breathing }\end{array}$ & 2 & 1 \\
$\quad$ management) & & \\
$\begin{array}{l}\text { Nutritionist } \\
\begin{array}{l}\text { Occupational therapist (energy } \\
\quad \text { conservation) }\end{array}\end{array}$ & 2 & 1 \\
$\begin{array}{l}\text { Respiratory therapist } \\
\quad \text { medication use techniques) }\end{array}$ & 2 & 1 \\
$\begin{array}{l}\text { Pulmonologist } \\
\quad \text { physiopathology, }\end{array}$ & 2 & 1 \\
$\quad \begin{array}{l}\text { prevalence, pharmacological } \\
\text { treatment, disease }\end{array}$ & & \\
$\quad$ management) & & \\
$\begin{array}{l}\text { Nurse (action plan) } \\
\text { Social worker }\end{array}$ & 1 & 1 \\
$\begin{array}{l}\text { Sex therapist } \\
\text { Tobacco cessation specialist }\end{array}$ & 1 & 1 \\
\hline
\end{tabular}

repetition (1RM) for targeted strength training exercises are also done for clinical research purposes.

\section{Self-management teaching program}

Patients are invited to attend group teaching sessions with their significant others on a variety of themes, with the common goal of promoting self-management strategies based on the model "Living well with COPD" (link: http://www.livingwellwithcopd.com/; password: copd). Overall, 18 sessions are be offered (Table 2).

\section{Exercise training program}

Prescribing exercise requires knowledge and experience to interpret and use elements of the assessment, to plan a safe, challenging and tailored exercise program with clear objectives and an appropriate progression to optimize benefits. Exercise prescription takes into account respiratory and muscle limitations as well the indication and contraindications for exercise, the medication, the comorbidities and the particular preferences of each patient. As shown in Fig. 2, an exercise prescription should be composed of different parts, each divided into modality-durationintensity-frequency-progression.

In our program the activation (warm up) is the initial part of the aerobic training and it is done with the same modality for a few minutes, up to $5 \mathrm{~min}$, at a very low intensity $(20-40 \%$ of the heart rate (HR) reserve). It is followed by aerobic training which is usually a combination of cycling and walking. During the first weeks of the program, short bouts of exercise are favored but the objective is to train 3 times per week, for 30-40 min doing interval or continuous training at a heart rate that may reach the heart rate recorded at $80 \%$ of peak incremental exercise testing or $80 \%$ of the HR reserve. To help exercise intensity progression, 


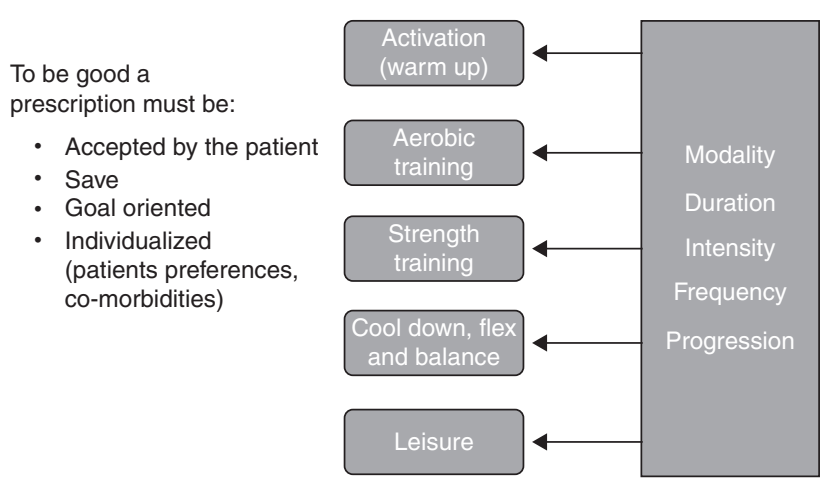

Figure 2 Exercise prescription in pulmonary rehabilitation.

we work on respiratory control which is helpful in reducing dyspnea perception.

Muscle training is usually conducted after aerobic training, when the body is well warmed up. Our muscle training program is aimed at promoting muscle strength and hypertrophic gains. In general, large muscle chains are chosen and a selection of exercises is prescribed 3 times per week. Each exercise should be performed for 2-3 series of 10 repetitions maximum. The use of training devices with selective weights is the usual modality but also available are isometric exercises, free weights, elastics bands, and medicine balls. To assure good progression, the number of repetitions should always be increased before increasing the weight.

The exercise session is completed with relaxation, cool down, flexibility and balance exercises that are tailored to the patients' needs.

Once a week, we have a period dedicated to recreational activities. We choose different ludic activities or sports to build team spirit and simply have fun. Leisure activities should be discussed and promoted outside of the program.

\section{Supervision of the program}

Exercise sessions are directly supervised by 2 exercise specialists, one kinesiologist and one physiotherapist, combining their expertise. Pursed lips breathing and breathing control are reinforced throughout the program. The use of the BORG scale is also promoted and is a key tool for assessing the perception of effort, fatigue and dyspnea. The professionals are always attentive and responsive to signs and symptoms related to effort intolerance, blood pressure, heart rate, glycemia (in diabetic patients), edema among others. ${ }^{6,10,47}$

The exercise specialists are experienced and, with a combination of knowhow and creativity, adapt the program to every patient's goals, capacities and limitations.

\section{Maintenance program}

Different maintenance strategies are offered to the patients during the program. It is important to prepare for the end of the program in such a way that they do not feel abandoned or without options; in this type of situation, they would be likely to return to sedentary lifestyle after rehabilitation. Home exercises are also taught during the self-management sessions.

\section{Post-program assessment}

Evaluating the patients at the end of the program will provide valuable information about the efficacy of the intervention and should help motivate patients to pursue an active life when they see the progress they have made. Demonstrating efficacy has also been instrumental in obtaining institutional recognition and financial support. The post-program evaluation includes constant cycling workrate exercise performed at pre-program intensity, 6-min walk test, body composition assessment (bioelectrical impedance and waist circumference) and the COPD Assessment Test (CAT).

\section{Home-rehabilitation program}

Undoubtedly, translating gains in exercise capacity with PR into a more active lifestyle is one of the main challenges in rehabilitation. ${ }^{16,19,24,48}$ Because home-based rehabilitation may be the most convenient, it may appear to be superior to center-based programs in terms of long term adherence to exercise. ${ }^{49}$ Thus, patients are encouraged to continue their training by either remaining in a hospital- or community-based program, or by initiating a home-based program. We are actively promoting home-based PR and hopefully will implement it locally on a bigger scale (for example, by encouraging the implementation and participation in different research projects such as home based PR or telerehabilitation ${ }^{25,50,51}$ ).

\section{Discussion}

Referral to a pulmonary program is an integral part of COPD management. Patient evaluation is mandatory before and after PR and ideally during any long-term follow-up assessment to quantify the impact of PR and to guide management. In addition to valid, responsive and interpretable laboratory-based exercise tests, field-based tests may be useful because of their ease of administration and relevance to daily life. Remaining challenges are the limited access to PR programs ${ }^{52}$ as well as maintaining initial benefits and their translation into active lifestyles. ${ }^{48}$ In this paper we have shared our own views about PR but we clearly encourage the creation of a diversity of programs and intervention to promote an active life style in a larger COPD population. These programs, however small they might be, should be well structured, done by a multidisciplinary team specifically trained in PR and tailored to the patients' needs. Moreover, when a program is available, its success clearly relies on the quality of care but also on the amount of promotion that we do. The local medical staff need to be aware that they can refer patients to a program but the information should transcend the local institution to ensure the sustainability of the program.

\section{Conflicts of interest}

The authors have no conflicts of interest to declare. 


\section{Ethical disclosures}

Protection of human and animal subjects. The authors declare that no experiments were performed on humans or animals for this study.

Confidentiality of data. The authors declare that no patient data appear in this article.

Right to privacy and informed consent. The authors declare that no patient data appear in this article.

\section{References}

1. Rabe KF, Hurd S, Anzueto A, Barnes PJ, Buist SA, Calverley $\mathrm{P}$, et al. Global strategy for the diagnosis, management, and prevention of chronic obstructive pulmonary disease: GOLD executive summary. Am J Respir Crit Care Med. 2007; 176:532-55.

2. Hurst JR, Vestbo J, Anzueto A, Locantore N, Mullerova $\mathrm{H}$, Tal-Singer R, et al. Susceptibility to exacerbation in chronic obstructive pulmonary disease. $N$ Engl J Med. 2010;363:1128-38.

3. Vestbo J, Hurd SS, Agusti AG, Jones PW, Vogelmeier C, Anzueto A, et al. Global strategy for the diagnosis, management, and prevention of chronic obstructive pulmonary disease: GOLD executive summary. Am J Respir Crit Care Med. 2013;187:347-65.

4. Weiner P, Magadle R, Berar-Yanay N, Davidovich A, Weiner M. The cumulative effect of long-acting bronchodilators, exercise, and inspiratory muscle training on the perception of dyspnea in patients with advanced COPD. Chest. 2000;118:672-8.

5. Pulmonary, rehabilitation-1999. American Thoracic Society. Am J Respir Crit Care Med. 1999;159 Pt 1:1666-82.

6. Pulmonary rehabilitation: joint, ACCP/AACVPR, evidencebased, guidelines; ACCP/AACVPR, Pulmonary Rehabilitation Guidelines, Panel; American College of Chest Physicians; American Association of Cardiovascular and Pulmonary Rehabilitation. Chest. 1997;112:1363-96.

7. British Thoracic Society Standards of Care Subcommittee on Pulmonary R. Pulmonary rehabilitation. Thorax. 2001;56:827-34.

8. Nici L, Donner C, Wouters E, Zuwallack R, Ambrosino N, Bourbeau J, et al. American Thoracic Society/European Respiratory Society statement on pulmonary rehabilitation. Am J Respir Crit Care Med. 2006;173:1390-413.

9. Ries AL, Bauldoff GS, Carlin BW, Casaburi R, Emery CF, Mahler DA, et al. Pulmonary rehabilitation: joint ACCP/AACVPR evidence-based clinical practice guidelines. Chest. 2007;131 Suppl.:4S-2S.

10. Spruit MA, Singh SJ, Garvey C, Zuwallack R, Nici L, Rochester C, et al. An official American Thoracic Society/European Respiratory Society statement: key concepts and advances in pulmonary rehabilitation. Am J Respir Crit Care Med. 2013;188:e13-64.

11. Griffiths TL, Burr ML, Campbell IA, Lewis-Jenkins V, Mullins $\mathrm{J}$, Shiels K, et al. Results at 1 year of outpatient multidisciplinary pulmonary rehabilitation: a randomised controlled trial. Lancet. 2000;355:362-8.

12. Griffiths TL, Phillips CJ, Davies S, Burr ML, Campbell IA. Cost effectiveness of an outpatient multidisciplinary pulmonary rehabilitation program. Thorax. 2001;56:779-84.

13. Troosters T, Casaburi R, Gosselink R, Decramer M. Pulmonary rehabilitation in chronic obstructive pulmonary disease. Am J Respir Crit Care Med. 2005;172:19-38.

14. O’Donnell DE, Hernandez P, Kaplan A, Aaron S, Bourbeau J, Marciniuk D, et al. Canadian Thoracic Society recommendations for management of chronic obstructive pulmonary disease - 2008 update - highlights for primary care. Can Respir J. 2008;15 Suppl A:1A-8A.

15. Lacasse Y, Goldstein R, Lasserson TJ, Martin S. Pulmonary rehabilitation for chronic obstructive pulmonary disease. Cochrane Database Syst Rev. 2006:CD003793.

16. Troosters T, Gosselink R, Janssens W, Decramer M. Exercise training and pulmonary rehabilitation: new insights and remaining challenges. Eur Respir Rev. 2010;19:24-9.

17. Lacasse Y, Martin S, Lasserson TJ, Goldstein RS. Meta-analysis of respiratory rehabilitation in chronic obstructive pulmonary disease. A Cochrane systematic review. Eur Medicophys. 2007;43:475-85.

18. Jenkins S, Hill K, Cecins NM. State of the art: how to set up a pulmonary rehabilitation program. Respirology. 2010;15:1157-73.

19. Saey D, Bernard S, Gagnon P, et al. Pulmonary rehabilitation in chronic obstructive pulmonary disease. Panminerva Med. 2009;51:95-114.

20. Beauchamp MK, Nonoyama M, Goldstein RS, Hill K, Dolmage TE, Mathur S, et al. Interval versus continuous training in individuals with chronic obstructive pulmonary disease - a systematic review. Thorax. 2010;65:157-64.

21. Klijn P, van Keimpema A, Legemaat $M$, Gosselink R, van Stel $\mathrm{H}$. Nonlinear exercise training in advanced chronic obstructive pulmonary disease is superior to traditional exercise training. A randomized trial. Am J Respir Crit Care Med. 2013;188:193-200.

22. Vogiatzis I, Nanas S, Roussos C. Interval training as an alternative modality to continuous exercise in patients with COPD. Eur Respir J. 2002;20:12-9.

23. Sava F, Laviolette L, Bernard S, Breton MJ, Bourbeau J, Maltais F. The impact of obesity on walking and cycling performance and response to pulmonary rehabilitation in COPD. BMC Pulm Med. 2010;10:55

24. Hill K, Vogiatzis I, Burtin C. The importance of components of pulmonary rehabilitation, other than exercise training, in COPD. Eur Respir Rev. 2013;22:405-13.

25. Maltais F, Bourbeau J, Shapiro S, Lacasse Y, Perrault H, Baltzan $M$, et al. Effects of home-based pulmonary rehabilitation in patients with chronic obstructive pulmonary disease: a randomized trial. Ann Intern Med. 2008;149:869-78.

26. Puente-Maestu L, Sanz ML, Sanz P, Ruiz de Ona JM, RodriguezHermosa JL, Whipp BJ. Effects of two types of training on pulmonary and cardiac responses to moderate exercise in patients with COPD. Eur Respir J. 2000;15:1026-32.

27. Maltais F, Bernard S, Jobin J, Belleau R, Leblanc P. Lactate kinetics during exercise in chronic obstructive pulmonary disease. Can Respir J. 1997;4:251-7.

28. Cambach W, Chadwick-Straver RVM, Wagenaar RC, van Keimpema ARJ, Kemper HCG. The effects of a community-based pulmonary rehabilitation programme on exercise tolerance and quality of life: a randomized controlled trial. Eur Respir J. 1997;10:104-13.

29. Wedzicha JA, Bestall JC, Garrod R, Garnham R, Paul EA, Jones PW. Randomized controlled trial of pulmonary rehabilitation in severe chronic obstructive pulmonary disease patients, stratified with the MRC dyspnoea scale. Eur Respir J. 1998;12:363-9.

30. Guell R, Casan P, Belda J, Sangenis M, Morante F, Guyatt GH, et al. Long-term effects of outpatient rehabilitation of COPD: a randomized trial. Chest. 2000;117:976-83.

31. American Thoracic S, American College of Chest P. ATS/ACCP statement on cardiopulmonary exercise testing. Am J Respir Crit Care Med. 2003;167:211-77.

32. Laviolette L, Bourbeau J, Bernard S, Lacasse Y, Pepin V, Breton MJ, et al. Assessing the impact of pulmonary rehabilitation on functional status in COPD. Thorax. 2008;63:115-21.

33. Borel B, Provencher S, Saey D, Maltais F. Responsiveness of various exercise-testing protocols to therapeutic interventions in COPD. Pulm Med. 2013;2013:410748. 
34. Laboratories ATSCoPSfCPF. ATS statement: guidelines for the six-minute walk test. Am J Respir Crit Care Med (Baltimore). 2002;166:111-7.

35. Garcia-Rio F, Lores V, Mediano O, Rojo B, Hernanz A, LópezCollazo E, et al. Daily physical activity in patients with chronic obstructive pulmonary disease is mainly associated with dynamic hyperinflation. Am J Respir Crit Care Med. 2009; 180:506-12.

36. Singh SJ, Morgan MD, Scott S, Walters D, Hardman AE. Development of a shuttle walking test of disability in patients with chronic airways obstruction. Thorax. 1992;47:1019-24.

37. Robles PG, Mathur S, Janaudis-Fereira T, Dolmage TE, Goldstein RS, Brooks D. Measurement of peripheral muscle strength in individuals with chronic obstructive pulmonary disease: a systematic review. J Cardiopulm Rehabil Prev. 2011;31:11-24.

38. Hopkinson NS, Tennant RC, Dayer MJ, Swallow EB, Hansel TT, Moxham J, et al. A prospective study of decline in fat free mass and skeletal muscle strength in chronic obstructive pulmonary disease. Respir Res. 2007;8:25.

39. American College of Sports M. American College of Sports Medicine position stand. Progression models in resistance training for healthy adults. Med Sci Sports Exerc. 2009;41:687-708.

40. Ritti-Dias RM, Avelar A, Salvador EP, Cyrino ES. Influence of previous experience on resistance training on reliability of onerepetition maximum test. J Strength Cond Res/Natl Strength Cond Assoc. 2011;25:1418-22.

41. Sala E, Roca J, Marrades RM, Alonso J, Gonzalez De Suso JM, Moreno A, et al. Effects of endurance training on skeletal muscle bioenergetics in chronic obstructive pulmonary disease. Am J Respir Crit Care Med. 1999;159:1726-34.

42. Vilaro J, Rabinovich R, Gonzalez-deSuso JM, Troosters T, Rodríguez D, Barberà JA, et al. Clinical assessment of peripheral muscle function in patients with chronic obstructive pulmonary disease. Am J Phys Med Rehabil/Assoc Acad Physiatrist. 2009;88:39-46.

43. Coronell C, Orozco-Levi M, Mendez R, Ramirez-Sarmiento A, Galdiz JB, Gea J. Relevance of assessing quadriceps endurance in patients with COPD. Eur Respir J. 2004;24:129-36.

44. Albert RK. Is pulmonary rehabilitation an effective treatment for chronic obstructive pulmonary disease? No. Am J Respir Crit Care Med. 1997;155:784-5.

45. Jones NL. Clinical exercise testing, vol. 3. Philadelphia: W.B. Saunders; 1988.

46. Jones PW, Harding G, Berry P, Wiklund I, Chen WH, Kline Leidy N. Development and first validation of the COPD Assessment Test. Eur Respir J: Off J Eur Soc Clin Respir Physiol. 2009;34:648-54.

47. American College of Sports M. ACSM's guidelines for exercise testing and prescription. 6th ed; 2000. Philadelphia.

48. Soicher JE, Mayo NE, Gauvin L, Hanley JA, Bernard S, Maltais F, et al. Trajectories of endurance activity following pulmonary rehabilitation in COPD patients. Eur Respir J: Off J Eur Soc Clin Respir Physiol. 2012;39:272-8.

49. Ashworth NL, Chad KE, Harrison EL, Reeder BA, Marshall SC. Home versus center based physical activity programs in older adults. Cochrane Database Syst Rev. 2005:CD004017.

50. Debigaré R, Maltais F, Whittom F, Deslauriers J, LeBlanc P. Feasibility and efficacy of home exercise training before lung volume reduction. J Cardiopulm Rehabil. 1999;19:235-41.

51. Coats AJ, Clark AL, Piepoli M, Volterrani M, Poole-Wilson PA. Symptoms and quality of life in heart failure: the muscle hypothesis. Br Heart J. 1994;72 Suppl:S36-9.

52. Brooks D, Sottana R, Bell B, Hanna M, Laframboise L, Selvanayagarajah S, et al. Characterization of pulmonary rehabilitation programs in Canada in 2005. Can Respir J. 2007;14:87-92. 